\title{
Citation Analysis of the Journal of Bone Metabolism from Korean Citation Index, Web of Science, and Scopus
}

\author{
Byung-Ho Yoon', Bo Kwon Hwang', Eun-Ae Jung' ${ }^{2}$, Deog-Yoon Kim ${ }^{3}$ \\ 'Department of Orthopedic Surgery, Ewha Womans University, College of Medicine, Mokdong Hospital, Seoul; \\ ${ }^{2}$ Medical Library, Soonchunhyang University Bucheon Hospital, Bucheon; \\ ${ }^{3}$ Department of Nuclear Medicine, Kyung Hee University Hospital, Kyung Hee University School of Medicine, Seoul, Korea
}

\author{
Corresponding author \\ Deog-Yoon Kim \\ Department of Nuclear Medicine, Kyung Hee \\ University Hospital, 23 Kyungheedae-ro, \\ Dongdaemun-gu, Seoul 02447, Korea \\ Tel: +82-2-958-8211 \\ Fax: +82-2-968-1848 \\ E-mail: ksbmr@naver.com
}

Received: July 31, 2021

Revised: August 14, 2021

Accepted: August 17, 2021
Background: Nine years have passed since the Journal of Bone Metabolism (JBM) was launched as an English journal in 2012; it was finally included in Scopus in January 2019. Therefore, this study aimed to provide evidence of increased international recognition based on journal metrics and reflect on its efforts to be recognized as a top-notch journal. Methods: Databases, such as the Web of Science (WoS), Scopus, Korean Citation In$\operatorname{dex}(\mathrm{KCl})$, and citation indicators, including the impact factor (IF) and SCImago journal rank (SJR) were reviewed and calculated according to years, and the results were drawn. Furthermore, country-wise contributions and top-cited articles were also investigated. Results: The JBM 2020 IF was 2.17 in the WoS. The 2020 SJR in Scopus was 0.334, with a ranking of 165/219 (75.3\%) in the Endocrinology, Diabetes, and Metabolism category. The $2020 \mathrm{KCl}$ was 0.42 . Of 263 articles, 260 were citable (98.9\%), and of 176 original articles, 15 (8.5\%) were supported by research grants. The total citation of JBM has increased from 16 in 2014 to 141 in 2020; however, its KCl remained stationary from 0.29 in 2015 to 0.42 in 2020 . Conclusions: Currently, JBM is increasingly cited by international researchers than Korean researchers, indicating that the journal's content is valued at an international level. Its inclusion in PubMed Central appears to have increased its international relevance; however, publishing English-only articles may hinder its use domestically. Therefore, efforts should be made to increase citation rates and enhance domestic readership.

Key Words: Bibliometrics · Databases, factual · Journal Impact Factor · PubMed

\section{INTRODUCTION}

The Journal of Bone Metabolism (JBM) is the official English-language open ac-

Copyright @ 2021 The Korean Society for Bone and Mineral Research

This is an Open Access article distributed under the terms of the Creative Commons Attribution Non-Commercial License (https://creativecommons.org/licenses/by-nc/4.0/) which permits unrestricted non-commercial use, distribution, and reproduction in any medium, provided the original work is properly cited.

\section{KSBMR}

cess journal of the Korean Society for Bone and Mineral Research (KSBMR) and the Korean Society of Sarcopenia.[1] It is a peer-reviewed, quarterly publication covering clinical and basic science information relevant to physicians and researchers in the field of bone metabolism.[1] It was first published in 1994. We used the term 'Korean Journal of Bone Metabolism (ISSN 1598-107X PRINT)', which was the official title of the journal from 1994 to 2011, and then the journal has been remodeled to an English language journal (ISSN 2287-7029) to increase its international 
recognition in November 2012. It has been indexed in PubMed Central, PubMed, and Korean Citation Index (KCl) through the 2012 issues so that all papers from 2012 became freely accessible through the internet. A digital object identifier (DOI) was added beginning with the 2012 issues.

Recently, it was included in Scopus in February 2019 and almost 7 years have passed since the JBM was first included in PubMed Central/PubMed. It is this author's belief that inclusion in PubMed/Scoups is more important than open access for increasing citations of medical journals, because these are still the primary search tool for most medical researchers. Therefore, it is time to check whether the number of citations has increased. It would also be interesting to gather a variety of bibliometric indicators to understand the present position of the JBM in the field of orthopedics among various citation indicators including the 2-year impact factor (IF) calculated from Web of Science (WoS), Scopus, and $\mathrm{KCl}$. These findings will provide insight into managing the journal to obtain an elite reputation among researchers in related areas.

\section{METHODS}

\section{Database}

WoS is the citation database maintained by Thomson Reuters that covers 9,542 science journals and 3,552 social science journals and 1,852 arts and humanities journals.[2] Journal Citation Reports (JCR) provides citation indicators based on the WoS, such as the 2-year IF. Scopus is another citation database managed by Elsevier that contains over 39,000 journals in the sciences, social sciences, and arts and humanities.[3] The SCImago journal rank (SJR) provides a citation indicator based on Scopus. Because the journals included in calculating the JCR and the SJR differ, the 2 citation indicators turn out to be somewhat different. $\mathrm{KCl}$ is the citation database maintained by the Korean National Research Foundation since 2004 and the total number of journals was 5,907 in 2021.[4] The citation indicators are usually lower than those from JCR or SJR because it is based on only journals from Korea.

Following metrics were analyzed from the journal's homepage; number of citable and non-citable articles, citing year, citing authors' countries, publication type, editorial board members' countries, authors' countries, and number of original articles supported by grants. We also compared IF with that of $2 \mathrm{SCIE}$ journals (Journal of Bone and Mineral Metabolism from Japanese Society for Bone and Mineral Research and Archive of Osteoporosis from International Osteoporosis Foundation and analyzed the top 10 cited journals of JBM.

Data retrieval and analysis were done on May 282021.

\section{Calculation}

1) Total citations per year

This is the number of citations in a given year of a target journal regardless of its publication year in the citation database. Publication types of citable articles are review articles, original articles, brief reports, and case reports.

\section{2) Impact factor}

Obtaining these 2 measures from $\mathrm{KCl}$ and Scopus/SClmago Journal \& Country Rank was simple because the JBM is included in those 2 databases. As for the IF from the WoS, it was manually calculated from the database because the JBM is not yet indexed in the WoS as an SCIE journal.

It can be calculated as follows:

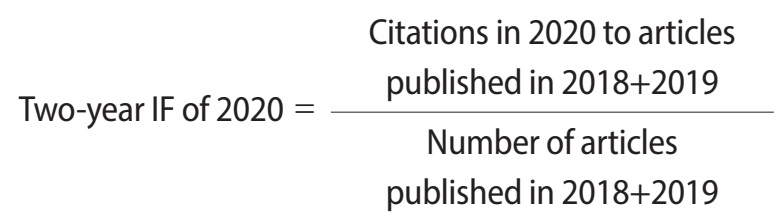

\section{3) SCImago Journal Rank}

This is calculated based on citation weighting schemes and eigenvector centrality. It reflects the "average prestige

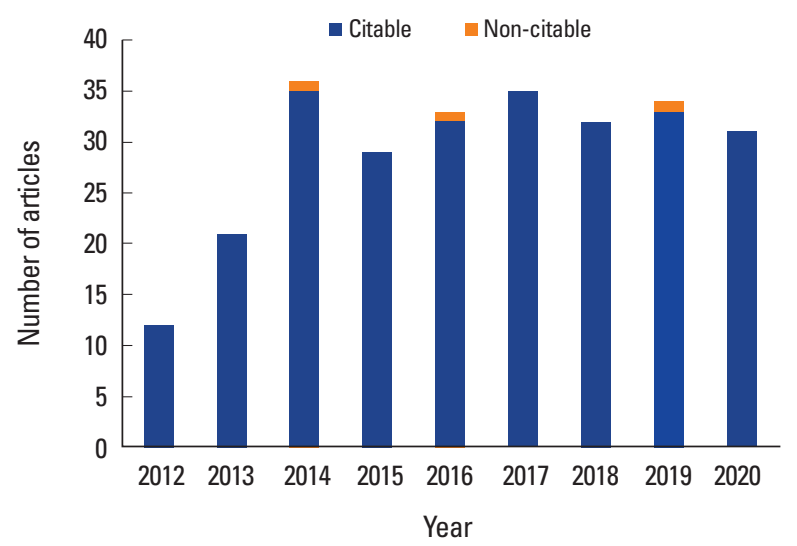

Fig. 1. Number of citable and non-citable articles of the Journal of Bone Metabolism. 
per article" so that when there are citations by high reputation journals, the SJR value increases more than with citations by low reputation journals. It reflects the prestige of the citing journal. For example, there are 2 journals with same impact index. If the highly prestigious journal cites 1 journal, its SJR becomes higher than the other journal's SJR. It was developed by Elsevier, and it is also a good indicator of the citation position of a journal in a category.

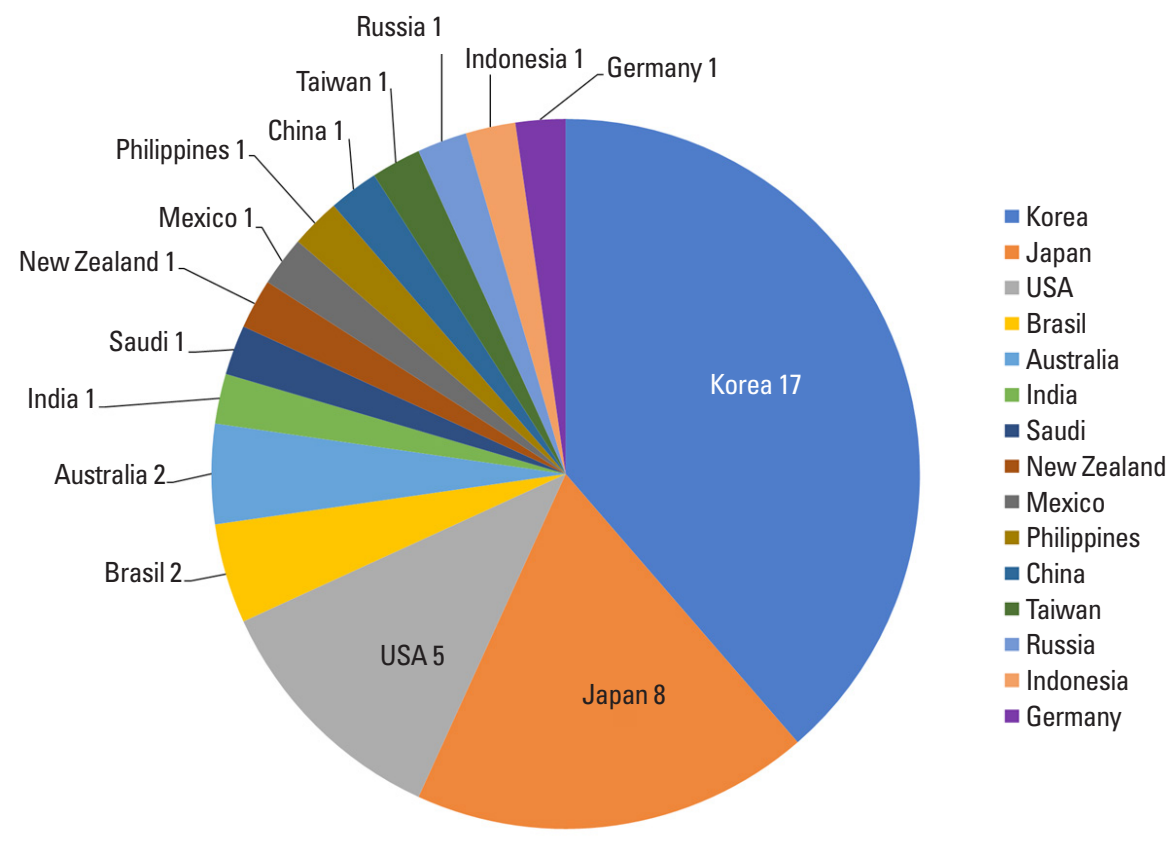

Fig. 2. Countries of editorial board members of the Journal of Bone Metabolism.

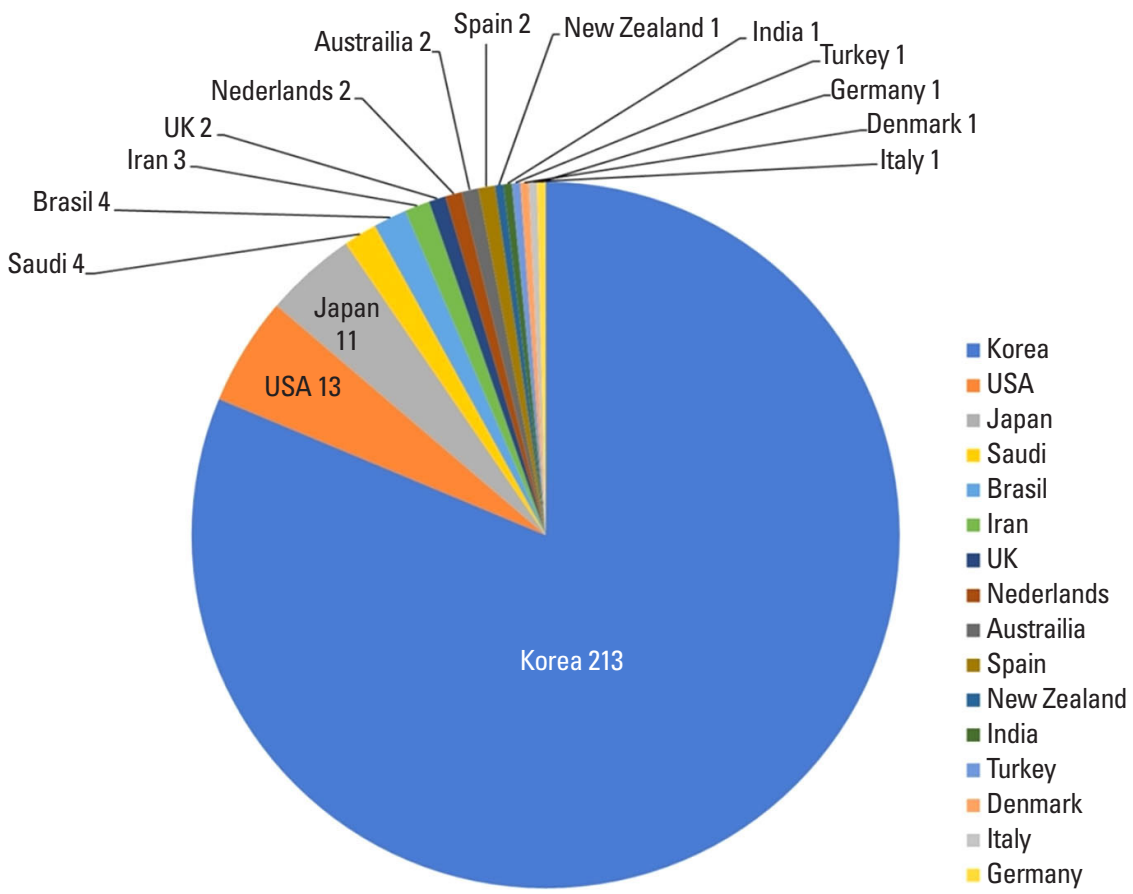

Fig. 3. Countries of authors of 263 articles published in the Journal of Bone Metabolism between 2012 and 2020. 


\section{RESULTS}

\section{General characteristics}

There was a steady increase in the number of articles published in JBM from 12 in 2012 to 141 in 2020. Accordingly, the number of citable articles has also grown during the same period: 260 (98.9\%) of the total 263 articles were citable articles (Fig. 1). Of the total 176 original articles, 15 (8.5\%) were supported by research grants. The editorial board consists of 44 specialists in their respective fields from 15 different countries: 17 from Korea, 8 from Japan, 5 from USA, and 14 from 12 other countries (Fig. 2). Authors of JBM were from 16 countries: most of the authors were Korean (213, 81.3\%), followed by USA (13, 5.0\%), Japanese (11, 4.2\%), and Brazil (4, 1.5\%) (Fig. 3).

\section{Total number and citation related index}

The total citation of JBM in WoS has increased from 16 in 2014 to 141 in 2020 . Of the 260 articles published between 2012 and 2020, 189 (72.7\%) were cited at least once by ar-

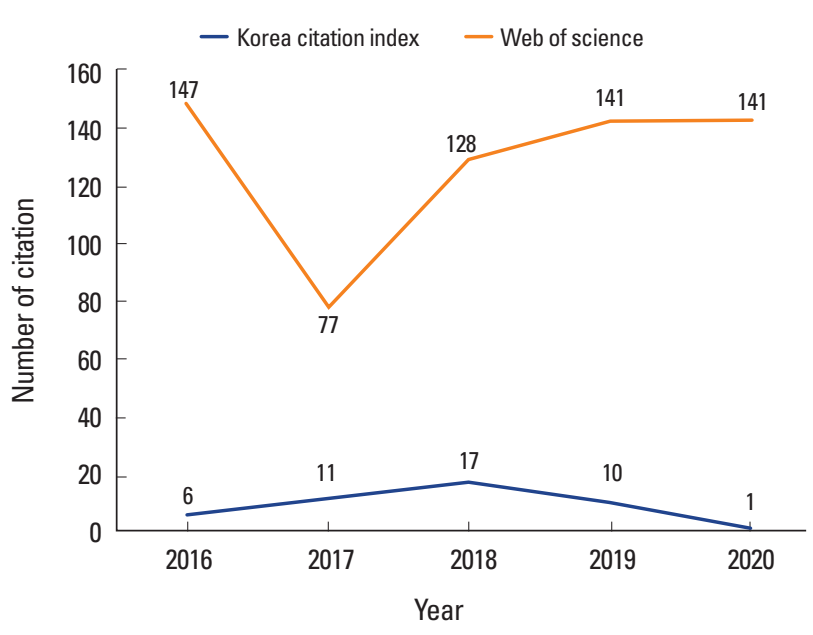

Fig. 4. Changing pattern of total citations of the Journal of Bone Metabolism articles from 2 databases (Web of Science and Korea Citation Index).

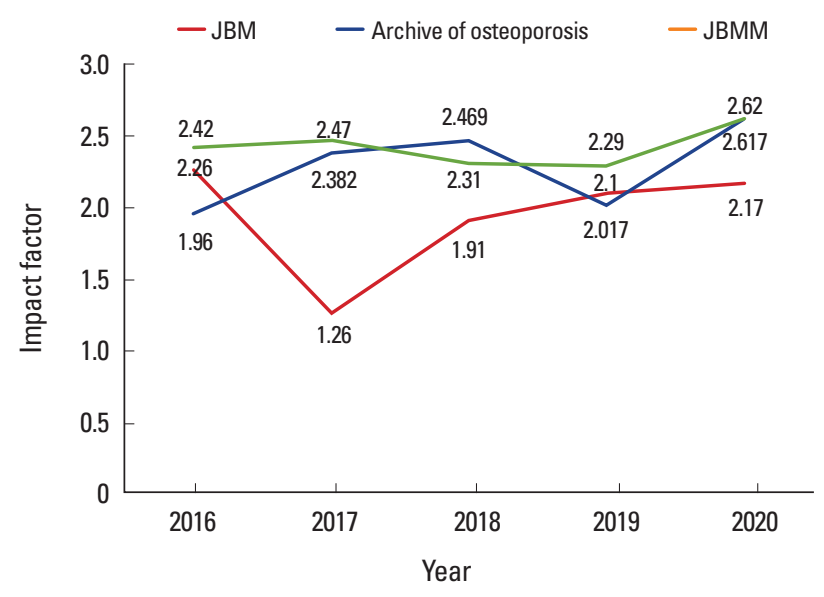

Fig. 5. Comparison of the impact factor without journal self-citations from Journal Citation Reports and Web of Science Core Collection database. JBM, Journal of Bone Metabolism; AO, Archives of Osteoporosis; JBMM, Journal of Bone Mineral Metabolism.

Table 1. Mostly highly cited papers of the Journal of Bone Metabolism from 2012 to 2020

\begin{tabular}{|c|c|c|c|c|c|c|c|}
\hline Rank & Year & Main author & $\begin{array}{l}\text { Citation } \\
\text { in WoS }\end{array}$ & $\begin{array}{l}\text { Citation } \\
\text { in } \mathrm{KCl}\end{array}$ & Title & $\begin{array}{l}\text { Article } \\
\text { type }\end{array}$ & Granted \\
\hline 1 & 2014 & Nacksung Kim & 228 & 19 & Regulation of NFATc1 in osteoclast differentiation & Review & $\mathrm{N}$ \\
\hline 2 & 2013 & Kyung Mook Choi & 180 & 12 & Sarcopenia: definition, epidemiology, and pathophysiology & Review & Y \\
\hline 3 & 2014 & Hiroshi Kaji & 73 & 8 & Interaction between muscle and bone & Review & $\mathrm{N}$ \\
\hline 4 & 2014 & Kyoji lkeda & 58 & 5 & $\begin{array}{l}\text { Factors and mechanisms involved in the coupling from bone resorption } \\
\text { to formation: how osteoclasts talk to osteoblasts }\end{array}$ & Review & Y \\
\hline 5 & 2014 & G. David Roodman & 58 & 2 & Pathobiology of Paget's disease of bone & Review & $\mathrm{N}$ \\
\hline 6 & 2014 & David J. Baylink & 51 & 2 & $\begin{array}{l}\text { Role of osteocyte-derived insulin-like growth factor I in developmental } \\
\text { growth, modeling, remodeling, and regeneration of the bone }\end{array}$ & Review & $\mathrm{N}$ \\
\hline 7 & 2017 & Yong-Chan $\mathrm{Ha}$ & 41 & 0 & $\begin{array}{l}\text { The efficacy of bisphosphonates for prevention of osteoporotic fracture: } \\
\text { an update meta-analysis }\end{array}$ & Original & Y \\
\hline 8 & 2014 & Hong-Wen Deng & 40 & 1 & Genome-wide association studies for osteoporosis: a 2013 update & Review & Y \\
\hline 9 & 2014 & T. John Martin & 40 & 4 & $\begin{array}{l}\text { Bone biology and anabolic therapies for bone: current status and future } \\
\text { prospects }\end{array}$ & Review & Y \\
\hline 10 & 2015 & Gun-II Im & 38 & 3 & $\begin{array}{l}\text { Effect of teriparatide on healing of atypical femoral fractures: a sys- } \\
\text { temic review }\end{array}$ & Review & $\mathrm{N}$ \\
\hline
\end{tabular}

WoS, Web of Science; KCl, Korea Citation Index; N, no; Y, Yes. 
ticles in the WoS. If the $2020 \mathrm{IF}$ from WoS (2.17) was applied to the $2020 \mathrm{JCR}$, JBM's ranking in the orthopedics category was in the upper $37 / 82$ (45.1\%) Meanwhile, the SJR ranking was 165/219 (75.3\%) in the category of Endocrinology, Diabetes and Metabolism. The IF could be stationary in $\mathrm{KCl}$ from 0.29 in 2015 to 0.42 in 2020; The total citation of JBM in $\mathrm{KCl}$ seems to be low compared to WoS (Fig. 4). However, JBM is still the most cited journal (1 of 9 journals) in the field of orthopedics from $\mathrm{KCl}$. The IF of competitive journals including the JBM are compared in Figure 5.

The publication types of the most frequently cited $10 \mathrm{ar}-$ ticles from 2012 to 2020 were review articles (9) and original articles (1) (Table 1). The publication types of the most frequently cited 10 articles from 2018 to 2020 were review articles (5), original articles (4), and guidelines (1) (Table 2).

\section{DISCUSSION}

Publication of 31 articles, the IF of 2.17, and the total citations of 141 are the evidences of evolution of JBM in 2020 into an internationally recognized journal. In addition, the editorial board includes 27 members outside the country, and authors from 16 different countries have contributed their works to our journal. Thus, JBM seems to deserve high recognition from the international community.

We can see the rapid increase in citation indicators such as the IF and annual total citations by SCIE journals after the language of the JBM was changed to English and the journal was included in PubMed Central/PubMed in 2010. We can see these kinds of phenomena consistently with other medical journals published in Korea.[5-7] Introduction of a variety of digital publication standards for scholarly journals was essential. This is likely due to the listing in PubMed Central/PubMed. This difference implies that if any papers are written in English and indexed in PubMed Central/PubMed, their chance of being cited by review writers increases such that writing papers in English is very important.

There are many factors that influence the journal to which an author chooses to submit. Authors are interested in submitting to journals with a high IF, as these journals are most frequently read and cited. It is unwise to judge the quality of research by citation rating alone, but we acknowledge the reality that without a high IF there are too few submissions. Although JBM has a publication history of 26 years, the journal has relatively low citation rates. We performed

Table 2. Mostly highly cited papers of the Journal of Bone Metabolism from 2018 to 2020

\begin{tabular}{|c|c|c|c|c|c|c|c|}
\hline Rank & Year & Main author & $\begin{array}{l}\text { Citation } \\
\text { in WoS }\end{array}$ & $\begin{array}{l}\text { Citation } \\
\text { in } \mathrm{KCl}\end{array}$ & Title & $\begin{array}{l}\text { Article } \\
\text { type }\end{array}$ & Granted \\
\hline 1 & 2018 & Yousef Nassar & 31 & 1 & $\begin{array}{l}\text { Proton-pump inhibitor use and fracture risk: an updated systematic } \\
\text { review and meta-analysis }\end{array}$ & Original & $\mathrm{N}$ \\
\hline 2 & 2018 & $\begin{array}{l}\text { Peter M. van der } \\
\text { Kraan }\end{array}$ & 24 & 0 & $\begin{array}{l}\text { Differential role of transforming growth factor-beta in an osteoarthritic } \\
\text { or a healthy joint }\end{array}$ & Review & $\mathrm{N}$ \\
\hline 3 & 2019 & Kyung-Hoi Koo & 13 & 0 & $\begin{array}{l}\text { Is there a role of pharmacological treatments in the prevention or } \\
\text { treatment of osteonecrosis of the femoral head?: a systematic re- } \\
\text { view }\end{array}$ & Review & $\mathrm{N}$ \\
\hline 4 & 2019 & Myung Jun Shin & 12 & 2 & Sarcopenia associated with chronic obstructive pulmonary disease & Review & Y \\
\hline 5 & 2018 & Dong-Won Byun & 12 & 2 & $\begin{array}{l}\text { Association between sarcopenia, sarcopenic obesity, and chronic dis- } \\
\text { ease in Korean elderly }\end{array}$ & Original & N \\
\hline 6 & 2018 & Byung-Ho Yoon & 12 & 3 & $\begin{array}{l}\text { Clinical utility of biochemical marker of bone turnover: fracture risk } \\
\text { prediction and bone healing }\end{array}$ & Review & $\mathrm{N}$ \\
\hline 7 & 2018 & $\begin{array}{l}\text { Sang Wan Kim/ } \\
\text { Yoon-Kyoung Sung }\end{array}$ & 11 & 4 & $\begin{array}{l}\text { Korean guideline for the prevention and treatment of glucocorticoid- } \\
\text { induced osteoporosis }\end{array}$ & Guideline & Y \\
\hline 8 & 2018 & Hyeon Chang Kim & 11 & 2 & $\begin{array}{l}\text { Association of insulin resistance with lower bone volume and strength } \\
\text { index of the proximal femur in nondiabetic postmenopausal women }\end{array}$ & Original & Y \\
\hline 9 & 2018 & Yong-Chan $\mathrm{Ha}$ & 11 & 1 & $\begin{array}{l}\text { Review of epidemiology, diagnosis, and treatment of osteosarcopenia } \\
\text { in Korea }\end{array}$ & Review & $\mathrm{N}$ \\
\hline 10 & 2019 & Young-Kyun Lee & 10 & 0 & $\begin{array}{l}\text { Influence of thyroid-stimulating hormone suppression therapy on bone } \\
\text { mineral density in patients with differentiated thyroid cancer: a } \\
\text { meta-analysis }\end{array}$ & Original & Y \\
\hline
\end{tabular}

WoS, Web of Science; KCl, Korea Citation Index; N, no; Y, Yes. 
a citation analysis to determine our current position as international journal and achieve excellent bibliographical status soon.

Several strategies may improve our citation rate; First, studies presented at major bone metabolism meetings, such as American Society for Bone and Mineral Research were often eventually published in other top-notched journals. Thus, we should focus our some effect to promote our journal to be submitted by participating in these conferences are necessary. Second, in recent years, many clinicians are thus likely to spend more time reading relevant social media including YouTube, Twitter and eventually recall the information to cite the mentioned articles. A positive correlation between social media and citation rates has been reported in several journals.[8-10] Such efforts as using visual abstracts on social media lead to increase readership and the IF by increasing the citation counts of their papers. Finally, we also keep basics to boost our citation including correct information and keywords and making our manuscript easily accessible.

We found that the major publication types of the most 10 frequently cited articles from our journals were review articles (Tables 1 and 2). Many clinicians do not have enough time to read many basic science research along with updated knowledge, review articles are easy to assess and cite.[11-13] However, given the relative quality of the field, it may have also influenced the fact that the main articles from our journal still were primarily limited to level III evidence. However, we do not believe that this lower level of evidence detracts from the value or importance of these articles. We expect that as our efforts continue to grow with time, additional studies with increasing patient cohort sizes and possibly higher levels of evidence will be conducted and published.

For achievement of such excellent bibliometric status, the editorial board members' laborious contribution and the KSBMR's financial support were also instrumental in the evolution of JBM into a notable journal. We believe JBM will become one of the most influential journals in the future considering the continued efforts to serve as a vehicle for communication of valuable information.

\section{CONCLUSIONS}

The citation indicators of the JBM vary according to the database. The strategy of switching to an English-language format allowed JBM to be cited more frequently by international researchers after being indexed in PubMed Central/PubMed. To be cited more frequently, good original articles and high-quality review articles should be contributed. And efforts to increase the citation rate and increase the domestic readership should also be continued.

\section{DECLARATIONS}

\section{Ethics approval and consent to participate Not applicable.}

\section{Conflict of interest}

No potential conflict of interest relevant to this article was reported.

\section{ORCID}

Byung-Ho Yoon https://orcid.org/0000-0001-8518-6331

Bo Kwon Hwang https://orcid.org/0000-0001-8407-272X

Eun-Ae Jung https://orcid.org/0000-0002-1135-6286

Deog-Yoon Kim https://orcid.org/0000-0003-4054-0231

\section{REFERENCES}

1. Korean Society for Bone and Mineral Research. About JBM. 2021 [cited by 2021 Jul 20]. Available from: https://www. ksbmr.org/eng/

2. Clarivate. Web of Science. 2021 [cited by 2021 Jul 20]. Available from: https://webofknowledge.com/

3. Elsevier. Scopus. 2021 [cited by 2021 Jul 20]. Available from: https://www.scopus.com/

4. National Research Foundation of Korea. Korean Citation index. 2021 [cited by 2021 Jul 20]. Available from: https:// www.kci.go.kr/kciportal/main.kci

5. Huh S. Citation analysis of The Korean Journal of Internal Medicine from KoMCl, Web of Science, and Scopus. Korean J Intern Med 2011;26:1-7. https://doi.org/10.3904/kjim. 2011.26.1.1.

6. Huh S. Citation analysis of the Korean Journal of Urology From Web of Science, Scopus, Korean Medical Citation Index, KoreaMed Synapse, and Google Scholar. Korean J Urol 2013;54:220-8. https://doi.org/10.4111/kju.2013.54.4.220.

7. Huh S. How far has The Korean Journal of Internal Medicine advanced in terms of journal metrics? Korean J Intern 
Med 2013;28:635-8. https://doi.org/10.3904/kjim.2013.28. 6.635 .

8. Jeong JW, Kim MJ, Oh HK, et al. The impact of social media on citation rates in coloproctology. Colorectal Dis 2019;21: 1175-82. https://doi.org/10.1111/codi.14719.

9. Hayon S, Tripathi H, Stormont IM, et al. Twitter mentions and academic citations in the urologic literature. Urology 2019;123:28-33. https://doi.org/10.1016/j.urology.2018.08. 041.

10. Ozkent MS, Böcü K, Altintas E, et al. Correlation between Twitter mentions and academic citations in sexual medicine journals. Int J Impot Res 2021. https://doi.org/10.1038/ s41443-021-00457-0.

11. Lai P, Liu YH, Xue JH, et al. The 100 most-cited articles on aortic dissection. BMC Cardiovasc Disord 2017;17:30. https: //doi.org/10.1186/s12872-016-0426-9.

12. Liu YH, Wang SQ, Xue JH, et al. Hundred top-cited articles focusing on acute kidney injury: a bibliometric analysis. BMJ Open 2016;6:e011630. https://doi.org/10.1136/bmjopen-2016-011630.

13. Heng Wong MY, Tan NYQ, Sabanayagam C. Time trends, disease patterns and gender imbalance in the top 100 most cited articles in ophthalmology. Br J Ophthalmol 2019;103: 18-25. https://doi.org/10.1136/bjophthalmol-2018-312388. 
